\title{
An Analysis of Business Communication Courses in Business Schools and Suggestions for Curriculum Development
}

\section{Hyejung Chang', Philip Park', Sujin Cho}

'Kyung Hee University School of Management, Seoul, Korea;

${ }^{2}$ Kyung Hee University Graduate College, Seoul, Korea

Objectives: The concept of communication is inherently broad, so the content of a course usually depends on the instructor, leading to a variety of syllabuses with a shared name. The present research was conducted to understand the current state of business communication courses in Korea and provide a fundamental basis for curriculum development.

Methods: The top 30 universities in the 2017 Business School Assessment by the Korea Economic Daily were accessed through websites. Department curriculum and course syllabuses were collected and analyzed and compared with those of 2011 and 2014 and with those from the top 30 American universities.

Results: Three types of business communication courses were identified, and the distribution of courses showed relatively balanced weights of the three types (46\%,24\%, and 30\%), which did not significantly change between 2011 and 2017. However, a gradual growth of business major proportions was noticed from 2011 (77\%) to 2014 (92\%). There were also significant differences between Korea and the U.S.: There was a higher proportion of elective courses (84\%) in Korea, whereas most of the courses were business in practice-oriented type (70\%) and required courses (63\%) in the U.S.

Conclusions: More emphasis on business communication in business schools is needed with lower technical skills and higher required courses in Korea. A suggested framework of the House of Quality model will be useful for curriculum development considering multifaceted stakeholder needs in a rather scientific way to improve the education, research, and practice of business communication.

Key Words: Business Communication, Curriculum, Web Search, House of Quality, Business School

\section{Introduction}

It perhaps goes without saying that communication is a founda-

Received: Nov 3, 2017 Revised: Dec 4, 2017 Accepted: Dec 8, 2017

Corresponding author: Hyejung Chang

School of Management, Kyung Hee University, 26 Kyungheedae-ro,

Dongdaemun-gu, Seoul 02447, Korea

Tel: +82-2-961-9432, Fax:+82-2-961-0515, E-mail: hjchang@khu.ac.kr

This is an Open Access article distributed under the terms of the Creative Commons Attribution Non-Commercial License (http://creativecommons.org/licenses/by$\mathrm{nc} / 4.0 /$ ) which permits unrestricted non-commercial use, distribution, and reproduction in any medium, provided the original work is properly cited. Copyright $\odot 2018$ Korean Association for Business Communication. tional aspect of business. In addition to communication's role in strengthening connections between stakeholders (Bourne, 2010), effective communication also leads to making better decisions, solving problems more efficiently, noticing problems more quickly, increasing productivity, developing business relationships, clarifying marketing messages, engaging more employees, and, ultimately, improving financial results. Smith and Savoian (1991), in their survey of $500 \mathrm{CEOs}$, listed three key factors to career success as integrity, interpersonal skills, and communication.

In spite of the importance of communication, however, busi- 
ness departments seem to take a more traditional, functional approach in their curriculum, focusing on classes such as marketing and finance and considering communication a secondary elective. With little interest in communication, its role is undervalued, which often leads to communication courses not being included as a requirement for a business degree and few courses being taught by full-time faculty (Russ, 2009). In Korea, although most university business departments offer communication courses, the content and style of a particular business communication course usually depends on what the instructor wishes to teach, which leads to a variety of syllabuses for different courses with a shared name (Chang, 2016).

In the business world, the concept of communication is inherently broad and complex, as communication occurs formally and informally with three distinct directions (downward, upward, and horizontal) at the individual, group, and organization level ( Bovee, Thill, \& Schatzman, 2003; Johnson, Donohue, Atkin, \& Johnson, 1994; Lunenburg \& Ornstein, 2008). For example, formally, internal communication occurs downward (supervisor to employee), upward (feedback to downward communication), and horizontally (interaction between organizational units on the same hierarchical level). Externally, formal communication occurs in marketing and public relations. Informally, internal communication occurs through the grapevine, while informal external communication occurs at industry gatherings and in social networking.

Another factor that contributes to the diversity of business communication courses is the fact that the topic of communication falls under communications, linguistics, and humanities, which means that the topic lends itself to an interdisciplinary approach. Advertisements, publicity, cultural differences, and information technology can all be studied as media of communication. Thus, with the variety of possible topics covered under the broader theme of communication, the focus of the course is inevitably determined by the instructor.

In an effort to provide data aimed at improving business curriculum and ultimately contribute to the world of business, this study is conducted to survey the current state of business communication courses in business schools in Korea. After providing a general examination of this state, we will analyze the objectives, content, and methods of these courses. After comparing Korean courses with American courses, we will pinpoint some of the weaknesses of the former. It is our hope that the results of this study can help provide a framework for a curriculum that addresses the needs of the stakeholders in the management process and ultimately improves communication in business contexts.

\section{Methods}

\section{Target Business Schools}

This paper examines the top 30 universities in Korea. These universities are listed in the 2016 Business School Assessment by the Korean Economic Daily (Korea Economic Daily, 2017), a ranking that is based on the evaluations of human resources directors representing 200 Korean corporations and considered to be a standard by both academia and industry. This assessment is based on scores for criteria such as "Professional Relevance of Education," "Organizational Adaptability," "Potential to Develop," "Creativity," "Globalized Curriculum," and "Responsibility." Our study examines the universities who ranked in the top 30 in this assessment.

In order to make a comparison, the top 30 American universities were also surveyed, as we expected their business schools to offer a more comprehensive curriculum with a greater emphasis on communication. We used the Best Undergraduate Business Programs Rankings, which is published by U.S. News (U.S. News, 2017). With overlap rankings included, 31 universities were examined.

\section{Data Collection}

We searched the websites of the targeted universities for each country and found the business major requirements for each university as well as the syllabuses for communication-related courses offered in 2017. For the Korean universities, excluding the 1 university (3.3\%) for which courses were not accessible and the 7 (24.1\%) universities that did not offer a communication-related course, information was collected regarding the remaining 22 universities, which together offered a total of 50 different courses. For the American universities, excluding the 10 universities that did not offer a business communication course and the 2 universities that offered such a course only at the graduate level (i.e., a total of 38.7\%), information was collected regarding the remaining 19 universities and the 24 different business communication courses they offer. Information regarding the courses covered themes such as course objectives, class type (general education vs. business major, required vs. elective), lecture content, instructor, and tasks.

\section{Analysis Methods}

Information regarding the objectives and content of each course was used to divide the courses into three types, which were identified in previous research (Chang, 2016). These 3 types of business communication $(\mathrm{BC})$ courses were those that focused on: (1) Business practice, such as cross-cultural or organizational skills, (2) Technical skills, such as speaking or writing, and (3) 
Specialized functions, such as marketing or negotiation. After the courses were divided into these types, they were examined to see whether they were a general education or business major course and whether they were required or an elective.

Proportions based on these characteristics were compared to those at different times and to those of the American universities; specifically, the 2017 proportions of the Korean universities were compared to those from 2011 and 2014 and to those of the American universities from 2017. The proportions of courses that were business major courses and those that were general education courses were also compared by year and by country using the Chi-Square Test at the 0.05 of significance level. The Fisher's Exact Test was used in cases of low frequencies in the contingency table, which does not meet the assumptions of the Chi-Square Test. Furthermore, the factors (country and business communication types) that might affect the proportions of required courses were analyzed using categorical data modeling, as this kind of modeling specializes in the analysis of a wide range of models on contingency tables (SAS, 2008). All the quantitative analyses were conducted using SAS version 9.4 (SAS Institute Inc., Cary, NC, USA).

\section{Results}

\section{Three Types of BC Courses}

The examined 50 courses were divided into 3 types (Table 1).
The first type of business communication course focuses on communication skills needed in the business world. Specifically, these courses focus on the improvement of communication skills, the role of communication in organizations, strategic communication, and intercultural communication for a globalized society. They also cover themes such as the business environment, language, identity, culture, decision-making, conflict resolution, culture (high-context cultures and low-context cultures), and group communication.

The second type of business communication course focuses on the development of technical communication skills. Specifically, these courses focus on preparing students for interviews, English resumes and cover letters, business document writing, presentations, and marketing oneself as a competitive candidate and employee in the future. They also emphasize people skills, relationship-building, interviewing strategies, etiquette, and leadership.

The third type of business communication course focuses on specialized forms of communication focusing on specific functions of business such as developing skills such as negotiation, STP (segmentation, targeting, and positioning), branding, and IMC (integrated marketing communication). They thus teach concepts and skills such as negotiation theory, marketing principles and communication processes, creative strategies for marketing, crisis management, customer management, and communication in social media.

Table 1. 3 types of business communication courses and their representative names in 2017

\begin{tabular}{lll}
\hline Type & \multicolumn{1}{c}{ Description } & Course name \\
\hline Type I & Business in practice: Business practice oriented such as cross-cultural or organizational & $\cdot$ Business Communication \\
& & $\cdot$ Global Business Communication \\
& & $\cdot$ Intercultural Communication \\
Type II & Technical skills: English improvement focused such as English speaking or writing & $\cdot$ Business Communication \\
& & $\cdot$ Business English Writing \\
Type III & Function-specific: Business function specific such as marketing or negotiation & $\cdot$ Business English \\
& & $\cdot$ Marketing Communication \\
& & $\cdot$ Business Negotiation \\
\end{tabular}

Table 2. Distribution of business communication courses by 3 course types

\begin{tabular}{|c|c|c|c|c|c|c|c|c|}
\hline \multirow{2}{*}{$\begin{array}{l}\text { Business commu- } \\
\text { nication type }\end{array}$} & \multicolumn{2}{|c|}{ Korea (2011) } & \multicolumn{2}{|c|}{ Korea (2014) } & \multicolumn{2}{|c|}{ Korea (2017) } & \multicolumn{2}{|c|}{ US (2017) } \\
\hline & $\mathrm{n}$ & $\%$ & $\mathbf{n}$ & $\%$ & $\mathbf{n}$ & $\%$ & $\mathbf{n}$ & $\%$ \\
\hline All & 54 & 100.0 & 40 & 100.0 & 50 & 100.0 & 24 & 100.0 \\
\hline Type I & 28 & 51.9 & 20 & 50.0 & 23 & 46.0 & 17 & 70.8 \\
\hline Type II & 18 & 33.3 & 10 & 25.0 & 12 & 24.0 & 3 & 12.5 \\
\hline Type III & 8 & 14.8 & 10 & 25.0 & 15 & 30.0 & 4 & 16.7 \\
\hline
\end{tabular}




\section{Distribution of Three Types of BC Courses}

\section{Distribution in Quantity}

In 2017, out of the 50 business communication courses, the majority were Type 1 ( $\mathrm{n}=23 ; 46 \%)$, with 12 (24\%) being Type 2 and 15 (30\%) being Type 3 (Table 2). When these proportions are compared to those of 2011 and 2014, the proportion of Type 2, which emphasizes technical skills, is seen to be decreasing (33\%, $25 \%, 24 \%)$, and that of Type 3, which emphasizes specialized communication, is seen to be growing $(15 \%, 25 \%, 30 \%)$. These differences of types by year, however, are not statistically significant at alpha 0.05 (Chi-Square $=3.87 ; \mathrm{df}=4 ; p=0.4238$ ). The type distribution of business communication courses in Korea is very different from that of business communication in the United States, with Type 1 courses constituting more than $70 \%$ of the business communication courses offered and Type 2 (13\%) and Type 3 (17\%) far behind. These differences in proportion between the two countries, however, are not statistically significant $($ Chi-Square $=4.03 ; \mathrm{df}=2 ; p=0.1333)$.

\section{Distribution by Characteristics}

When courses were compared by how they were categorized, i.e., general education vs. business major and required vs. elective, the results were as follows: In 2017, 94\% (47 out of 50) were offered within the business major, and only $16 \%$ (8 out of 50 ) were required courses (Table 3). When compared to the business major proportions in 2011 (77\%) and 2014 (92\%), we see a gradual growth that is statistically significant (Chi-Square $=7.98$; $\mathrm{df}=2 ; p=0.0185)$. On the other hand, for required courses, we observe a gradual decrease from 2011 (35\%) and 2014 (20\%), but this difference is not significant at alpha 0.05 (Chi-Square= $5.75 ; \mathrm{df}=2 ; p=0.564)$.

Looking at Table 3, we see that while in Korea, only $16 \%$ of the business communication courses were required in 2017, 63\% (15 out of 24) were required in the United States, a difference that is statistically significant (Chi-Square $=16.37 ; \mathrm{df}=1 ; p<0.0001$ ). Additionally, it is worth mentioning that while in Korea, general education and business major courses are divided into sub-categories such as general-required, general-basic, general-elective,

Table 3. Distribution of business communication courses by course characteristics

\begin{tabular}{|c|c|c|c|c|c|c|c|c|}
\hline \multirow{2}{*}{ Characteristics } & \multicolumn{2}{|c|}{ Korea (2011) } & \multicolumn{2}{|c|}{ Korea (2014) } & \multicolumn{2}{|c|}{ Korea (2017) } & \multicolumn{2}{|c|}{ US (2017) } \\
\hline & n & $\%$ & $\mathbf{n}$ & $\%$ & $\mathrm{n}$ & $\%$ & $\mathbf{n}$ & $\%$ \\
\hline All & 54 & 100.0 & 40 & 100.0 & 50 & 100.0 & 24 & 100.0 \\
\hline General education & 13 & 22.8 & 3 & 7.7 & 3 & 6.0 & 1 & 4.2 \\
\hline Business major & 44 & 77.2 & 36 & 92.3 & 47 & 94.0 & 23 & 95.8 \\
\hline Required & 19 & 35.2 & 8 & 20.0 & 8 & 16.0 & 15 & 62.5 \\
\hline Elective & 35 & 64.8 & 32 & 80.0 & 42 & 84.0 & 9 & 37.5 \\
\hline General-required & 7 & 13.0 & 1 & 2.4 & 2 & 4.0 & & \\
\hline General-basic & 5 & 9.3 & 3 & 7.3 & 0 & 0.0 & & \\
\hline General-elective & 1 & 1.9 & 0 & 0.0 & 1 & 2.0 & & \\
\hline Major-required & 5 & 9.3 & 2 & 4.9 & 2 & 4.0 & 15 & 62.5 \\
\hline Major-basic & 2 & 3.7 & 2 & 4.9 & 4 & 8.0 & & \\
\hline Major-elective & 31 & 57.4 & 28 & 68.3 & 35 & 70.0 & 9 & 37.5 \\
\hline Major-advanced & 3 & 5.6 & 5 & 12.2 & 6 & 12.0 & & \\
\hline
\end{tabular}

Table 4. Proportion of required courses by 3 business communication types

\begin{tabular}{|c|c|c|c|c|c|c|c|c|c|c|}
\hline & \multicolumn{4}{|c|}{ Korea (2017) } & \multicolumn{4}{|c|}{ US (2017) } & \multirow{2}{*}{\multicolumn{2}{|c|}{ Proportion (Required) }} \\
\hline & \multicolumn{2}{|c|}{ Required } & \multicolumn{2}{|c|}{ Elective } & \multicolumn{2}{|c|}{ Required } & \multicolumn{2}{|c|}{ Elective } & & \\
\hline & n & col\% & $\mathrm{n}$ & col\% & n & col\% & $\mathbf{n}$ & col\% & Korea (2017) & US (2017) \\
\hline All & 8 & 100 & 42 & 100 & 15 & 100 & 9 & 100 & 0.16 & 0.63 \\
\hline Type I & 8 & 100 & 19 & 45 & 7 & 47 & 6 & 67 & 0.30 & 0.54 \\
\hline Type II & 0 & 0 & 8 & 19 & 6 & 40 & 1 & 11 & 0.00 & 0.86 \\
\hline Type III & 0 & 0 & 15 & 36 & 2 & 13 & 2 & 22 & 0.00 & 0.50 \\
\hline Fisher's Exact test & & $p=0.00$ & $\mathrm{ob}=$ & 96; & & $p=0.05$ & $a b=$ & & & \\
\hline
\end{tabular}


Table 5. Maximum likelihood estimates of categorical data modelling for proportion of required courses in business communication

\begin{tabular}{llcccc}
\hline Parameter & & Estimate & $\begin{array}{c}\text { Standard } \\
\text { Error }\end{array}$ & $\begin{array}{c}\text { Chi- } \\
\text { Square }\end{array}$ & $\begin{array}{c}\text { Pr }> \\
\text { ChiSq }\end{array}$ \\
\hline Intercept & & -0.84 & 0.36 & 5.59 & 0.0180 \\
Country & 1 (Korea) & -1.08 & 0.30 & 12.92 & 0.0003 \\
Type & 1 (Type I) & 0.63 & 0.42 & 2.25 & 0.1338 \\
& 2 (Type II) & 0.39 & 0.50 & 0.62 & 0.4307 \\
\hline
\end{tabular}

major-required, major-basic, and major-elective, courses in the United States are simply divided into electives and required courses.

Table 4 presents the results from the division of types of required business communication courses offered in 2017. All 8 required courses were Type 1, and for electives, Type 1 constituted 45\%, Type $219 \%$, and Type $336 \%$, showing a statistically different distribution (Fisher's Exact probability=0.0196). According to the Categorical Data Modelling analysis results based on the required/elective distributions by country and course type, the difference between Korea and the United States was statistically significant in spite of the fact that the difference between business communication course types was not (Table 5).

\section{Discussion}

\section{Main Findings}

Based on the analysis of business communication courses in Korean universities, 3 types of business communication courses were identified: Business in practice, technical skills focused, and function-specific. The 3 types in Korea had almost balanced weights, while the proportion of "Business in practice" type was higher than $70 \%$ in the U.S. However, the proportion of courses teaching technical skills is decreasing and probably approaching that of the U.S. There were also significant differences between Korea and the U.S. in business communication courses; in particular, most of the courses in Korea were electives while those in the U.S. were required. These results show that business communication is seen as less important in Korean education.

The range of teaching goals in business communication courses in the United States is relatively broad. The goals include understanding the process of writing and speaking, understanding the ethical goals of business communication, problem solving and critical thinking in argument, case studies of effective business communication, communication skills in resumes, applications, and job interviews, preparation for business messages, official reports, and proposals, etc. Practically, based on a survey of 505 business communication instructors in the U.S. (Russ, 2009), the most common topics covered in business communi- cation were written communication, public speaking, persuasive and ethical communication, and the least common topics were business communication models/theories, mediated communication. This suggest that instructors place a stronger emphasis on teaching writing versus speaking skills and underscoring the course's historic focus on communication.

\section{Curriculum Development Needs}

Although business communication has recently been receiving more attention in Korea, it is still far from being considered a systematic academic discipline, as it lacks a great deal on both the quantitative and qualitative level. As Korean universities continue to develop in this field, they face the limitations of curriculum instability caused by a frequent restructuring of departments and an unstable pool of expert instructors. In order for us to see substantial development, we must prepare an educational framework that meets the demands of the times by developing a business communication curriculum that is organizational and strategically focused.

To establish such an educational system, curriculum development must start with the agreement of its objectives and goals and then lead a discussion of the factors they involve (Dick \& Carey, 1990). In the case of business, however, as the major offers an education that is not functional like many other majors, we face the difficulty of being largely dependent on educators in this field. Unlike universities in more developed countries, universities in Korea do not develop with the help of financial support over an extended period of time and consequently do not consider a variety of relevant factors, especially the factor of the changing demands of industry. In this context, Kemelgor, Johnson, and Srinivasan (2010) demonstrated that the importance of key forces driving organizational change will intensify in the future.

We can find cases from the development of university curriculums abroad. For example, in the United States, even in the 1990s, in an effort to revolutionize their curriculum, graduate programs conducted a survey that involved a wide range of stakeholders, not only professors but also administrative staff, students, alumnus, industry, and consultants. For example, Cornell University made a similar move when they mailed 290 surveys to a variety of stockholders including 106 industry professionals to design the curriculum (Enz, Renaghan, \& Geller, 1993). Recently in 2017, the faculty of INSEAD approved new components for their MBA curriculum after an extensive two-year review with input from important stakeholders, including faculty, students, alumni, staff, and recruiters (Manipur, 2017). INSEAD's ultimate goal remains the same, but the innovative new curriculum features a digital start and a more personalized learning journey. 


\section{A Framework for Curriculum Development}

An effective business education helps students overcome their weaknesses and prepares them to meet the needs of the business world. When looking at what employers expect of their employees, we see that they expect them to be able to organize ideas or information logically, communicate with a variety of people, behave politely, think ethically, know and follow regulations, use time productively, express ideas persuasively, and use technology effectively (Bovée \& Thill, 2010). This short list shows that employers realize that communication skills are key in strengthening networks with stakeholders.

It is possible to establish a curriculum that meets the demands of the educational process and the consumer, in which case the primary consumer would be the student and the ultimate consumer would be industry. As a consumer-focused education would aim to diversify the educational process to meet the demands of the consumer and manage the process at different levels (Huh, 2000). There are some recently who believe that a market-oriented education that meets the demands of industry would be more effective (Baily, 2000).

As a useful model of curriculum development that meets customer needs, the House of Quality (HoQ) model can be proposed (Griffin \& Hauser, 1993), as shown in Figure 1. The HoQ model translates customer demands into a concrete map of functions through the process of Quality Function Deployment (QFD), which is a method of addressing customer complaints beforehand (Karsak, Sozer, \& Alptekin, 2002) and is also a product

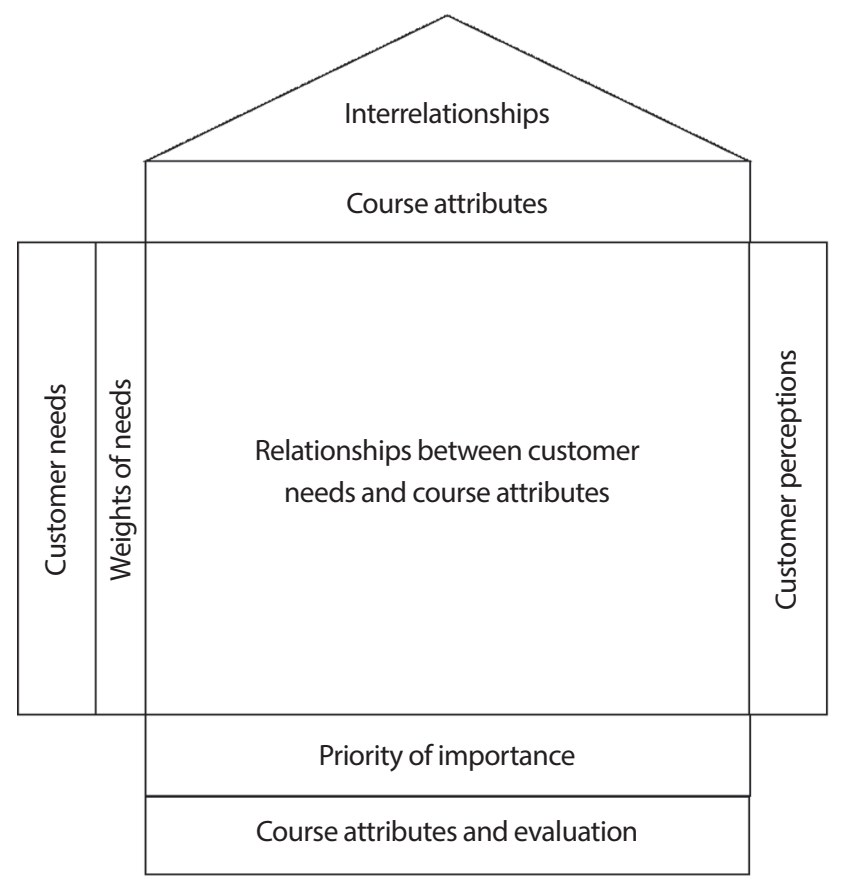

Figure 1. Basic model of the House of Quality (HoQ), adapted from Griffin \& Hauser (1993). development theory that maps out customer demands and reexamines process and production (Hauser \& Clausing, 1998). Developed in the late 1960s and used in diverse manufacturing settings, the QFD model allows for the systematic evaluation of functions in service industries such as shopping malls, hotels, restaurants, web design (Baran \& Yildiz, 2015; Chang \& Kim, 2010; Mazur, 1993; Park \& Noh, 2002; Tan, Xie, \& Chia, 1998), and has shown new potential in the field of education (Jnanesh \& Hebbar, 2008; Skordoulis et al., 2015).

The fact of utilizing the HoQ model in the establishment of a business communication curriculum means that all stakeholders are considered simultaneously in the establishment of the curriculum, signaling potential for more encompassing and flexible models for business communication. Most fundamentally, however, is the fact that from understanding the demands of the stakeholders in the educational process, the function elements of curriculum are derived based on scientific evidence. More practically, it is possible to address the customer demands through a survey of stakeholders and to reflect curriculum functions by utilizing the curriculum analysis results of this study. The interrelationships between demands and functions are analyzed using various statistical techniques such as correlation and Analytical Hierarchy AHP (Analytical Hierarchy Process), and the importance weights curriculum functions are derived from the comprehensive relational matrices (Bahil \& Chapman, 1993).

In summary, up to now, curriculum development has been biased towards the educational institution and lecturers. This study suggests that a stockholder-led, market-oriented business communication curriculum offers advantages for each of the stakeholders and also holds potential academic and industry development. Educators will be able to prepare for long-term growth as they see a growth in the development of research, and they will be able to build a curriculum base by writing textbooks. Through such efforts, it is expected that students will be more involved in the learning process, and stakeholders will see higher qualified prospective employees who meet industry needs.

\section{Conclusion}

This study is conducted to understand the current state of business communication education in business schools in Korea and to suggest a research framework to improve the curriculum. Specifically, the course contents of business communication in Korean universities are analyzed and compared with cases in the U.S. Three types of business communication courses were identified, and significant differences between Korea and the U.S. in business communication courses were found. In particular, there were relatively balanced weights of the 3 types and a 
higher proportion of elective courses in Korea, whereas most of the courses were business in practice-oriented type and required courses in the U.S. More emphasis on business communication in business schools is needed with lower technical skills and higher required courses in Korea. Curriculum is one of the main elements in education, and in order to achieve its goals, it needs to meet customer needs in business industry as well as education. A suggested framework of the HoQ model will be useful for curriculum development considering multifaceted stakeholder needs in a rather scientific way to improve the education, research, and practice of business communication.

\section{References}

Bahill, A. T., \& Chapman, W. L. (1993). A tutorial on quality function deployment. Engineering Management Journal, 5(3), 24-35.

Baily, J. J., \& Dangerfield, B. (2010). Applying the distinction between market-oriented and customer-led strategic perspectives to business school strategy. Journal of Management Education, 75(3), 183-187.

Baran, Z., \& Yildiz, M. S. (2015). Quality function deployment and application on a fast food restaurant. International Journal of Business and Social Science, 6(9), 122-131.

Bourne, L. (2010). Beyond reporting-the communication strategy. Paper presented at PMI ${ }^{\circledR}$ Global Congress 2010-Asia Pacific, Melbourne, Victoria, Australia. Newtown Square, PA: Project Management Institute.

Bovée, C. L., \& Thill, J. V. (2010). Business communication essentials (4th Ed), Upper Saddle River, New Jersey: Pearson.

Bovée, C. L., Thill, J. V., \& Schatzman, B. E. (2003). Business communication today (7th Ed), Upper Saddle River, NJ: Pearson.

Chang, H. (2016). Analysis of teaching trend on business communication. Proceedings of the Conference of Korean Association for Business Communication (pp. 22-28). Seoul, Korea.

Chang, H., \& Kim, D. (2010). A quality function deployment framework for the service quality of health information websites. Healthcare Informatics Research, 16(1), 6-14.

Dick, W., \& Carey, L. (1990). The systematic design of instruction. Glenview, IL: Scott, Foresman and Co.

Enz, C. A., Renaghan, L. M., \& Geller, A. N. (1993). Graduate-level education: A survey of stakeholders. Cornell Hotel and Restaurant Administration Quarterly, 34(4), 90-95. Retrieved from http:// scholarship.sha.cornell.edu/cgi/viewcontent.cgi?article=1465\&context=articles

Griffin, A., \& Hauser, J. R. (1993). The voice of the customer. Marketing Science, 12(1), 1-27.

Hauser, J. R., \& Clausing, D. (1998). The house of quality. Harvard Business Review, 66(3), 63-73.
Huh, H. G. (2000). A research about education for the demander from the viewpoint of cognitive developmental psychology. Journal of Curriculum Studies, 18(2), 159-177.

Jnanesh, N. A., \& Hebbar, C. K. (2008). Use of quality function deployment analysis in curriculum development of engineering education and models for curriculum design and delivery. Proceedings of the World Congress on Engineering and Computer Science, San Francisco, CA. Retrieved from http://www.iaeng.org/ publication/WCECS2008/WCECS2008_pp574-577.pdf

Johnson, J. D., Donohue, W. A., Atkin, C., K., \& Johnson, S. (1994). Differences between formal and informal communication channels. The Journal of Business Communication, 31(2), 111-122.

Karsak, E. E., Sozer, S., \& Alptekin, S. E. (2002). Product planning in quality function deployment using a combined analytic network process and goal programming approach. Computers and Industrial Engineering, 44(1), 171-190.

Kemelgor, B. H., Johnson, S. D., \& Srinivasan, S. (2010) Forces driving organizational change: A business school perspective. Journal of Management Education, 75(3), 133-137.

Korea Economic Daily. (2017). 2016 business school assessment rankings. Retrieved from http://magazine.hankyung.com/apps/ news? popu $p=0 \&$ nid $=01 \& c 1=1001 \&$ nkey $=2016112801096000191$ \&mode=sub_view

Lunenburg, F. C., \& Ornstein, A. O. (2008). Educational administration: Concepts and practices. Belmont, CA: Cengage/Wadsworth.

Manipur, C. (2017). Introducing the new MBA curriculum. Retrieved from https://alumnimagazine.insead.edu/introducing-the-newmba-curriculum/

Mazur, G. H. (1993) QFD for service industries: From voice of customer to task deployment. Proceedings of the 5th Symposium on Quality Function Deployment. Novi, MI. Retrieved from http:// mazur.net/works/svctaskqfd.pdf

Park, H. S., \& Noh, S. J. (2002) Enhancement of web design quality through the QFD approach. Total Quality Management, 13(3), 393-401.

Russ, T. L. (2009). The status of the business communication course at U.S. colleges and universities. Business Communication Quarterly, 72(4), 395-413.

SAS Institute Inc. (2008). SAS/STAT ${ }^{\circledR} 9.2$ User's Guide. Cary, NC: Author.

Skordoulis, M., Sparangis, P., Stampolis, O., Mougkolia, I., Papageorgiou, A., \& Chondreli, C. (2015, September). A framework for quality in education: Applying quality function deployment to a higher education institute. Paper presented at the 10th ERA International Scientific Conferences. Aigáleo, Greece

Smith, K. V., \& Savoian, R. (1991). Climbing to the top: Rising through the corporate ladder. Review of Business. Retrieved from https://www.highbeam.com/doc/1G1-12139265.html 
Tan, K. C., Xie, M., \& Chia, E. (1998). Quality function deployment and its use in designing information technology systems. International Journal of Quality \& Reliability Management, 15(6), 634-
645.

U.S. News. (2017). Best undergraduate business programs. Retrieved from https://www.usnews.com/best-colleges/rankings/business 